\title{
Human TERT promoter mutations as a prognostic biomarker in glioma
}

\author{
Branka Powter ${ }^{1}$. Sarah A. Jeffreys ${ }^{1,2} \cdot$ Heena Sareen ${ }^{1,3} \cdot$ Adam Cooper $^{1,2,4} \cdot$ Daniel Brungs $^{1,5} \cdot$ Joseph Po ${ }^{1}$. \\ Tara Roberts ${ }^{2,3} \cdot$ Eng-Siew $\mathrm{Koh}^{3,4} \cdot$ Kieran F. Scott $^{1,2} \cdot$ Mila Sajinovic $^{1}$ - Joey Y. Vessey ${ }^{4}$ Paul de Souza ${ }^{1,2,3,4,5}$. \\ Therese M. Becker ${ }^{1,2,3}$
}

Received: 16 October 2020 / Accepted: 15 January 2021 / Published online: 6 February 2021

(c) The Author(s) 2021

\begin{abstract}
The TERT promoter ( $p T E R T$ ) mutations, C228T and C250T, play a significant role in malignant transformation by telomerase activation, oncogenesis and immortalisation of cells. C228T and C250T are emerging as important biomarkers in many cancers including glioblastoma multiforme (GBM), where the prevalence of these mutations is as high as $80 \%$. Additionally, the rs2853669 single nucleotide polymorphism (SNP) may cooperate with these $p T E R T$ mutations in modulating progression and overall survival in GBM. Using liquid biopsies, $p T E R T$ mutations, C228T and C250T, and other clinically relevant biomarkers can be easily detected with high precision and sensitivity, facilitating longitudinal analysis throughout therapy and aid in cancer patient management.

In this review, we explore the potential for $p T E R T$ mutation analysis, via liquid biopsy, for its potential use in personalised cancer therapy. We evaluate the relationship between $P T E R T$ mutations and other biomarkers as well as their potential clinical utility in early detection, prognostication, monitoring of cancer progress, with the main focus being on brain cancer.
\end{abstract}

Keywords Glioma $\cdot$ Biomarker $\cdot$ TERT promoter mutation $\cdot$ Liquid biopsy $\cdot \operatorname{ctDNA}$

\section{Introduction}

Telomerase reverse transcriptase (TERT) plays an important role in telomere lengthening and oncogenesis in many human cancers (Moyzis et al. 1988). Two particular mutations in the human TERT promoter ( $p T E R T)$ region, C228T and $\mathrm{C} 250 \mathrm{~T}$, are important as they promote the formation of a novel binding site for transcriptional enhancers. This in turn drives increased expression and activity of telomerase,

Branka Powter

branka.powter@inghaminstitute.org.au

1 Centre for Circulating Tumour Cell Diagnostics and Research, Ingham Institute for Applied Medical Research, 1 Campbell St, Liverpool, NSW 2170, Australia

2 School of Medicine, Western Sydney University, Campbelltown, NSW 2560, Australia

3 Western Clinical School, University of New South Wales South, Goulburn St, Liverpool, NSW 2170, Australia

4 Cancer Therapy Centre, Liverpool Hospital, Elizabeth St and Goulburn St, Liverpool, NSW 2170, Australia

5 School of Medicine, University of Wollongong, Wollongong, NSW 2522, Australia an event considered critical for cell immortalisation, and a hallmark of oncogenesis (Hanahan and Weinberg 2011; Huang et al. 2015).

pTERT C228T and C250T have been identified in a range of cancers, including primary brain cancers, and are associated with reduced overall survival (OS), suggesting that they may serve as genomic cancer biomarkers (You et al. 2017). Cancer biomarkers are increasingly used in determining disease diagnosis, monitoring of progression, and determining the best outcome-based therapy for patients. Several studies indicate that the presence of $p T E R T$ mutations are tightly linked with other biomarkers such as EGFR amplification, IDH wild type (in GBM), 1p19q co-deletion, CDKN2A deletion, chromosome 10q loss and SEL1L, suggesting evolutionary co-selection with $p T E R T$ mutations (Labussière et al. 2014a; Mellai et al. 2020; Nonoguchi et al. 2013). In contrast, there is no association between $p T E R T$ mutations and other mutations such as IDH and TP53 (Labussière et al. 2014a).

Currently, there are few options for the treatment of brain cancers, regardless of their molecular profile. The Standardof-care treatment is maximal safe resection (where possible), followed by post-operative radiation and chemotherapy with 
adjuvant temozolomide (Stupp et al. 2010). Therefore, new treatment approaches are needed, which are tailored for each patient to improve patient outcomes.

In this review, we examine the effects of pTERT mutations in various cancers focusing on those originating in brain tissues. We also examine the interaction of pTERT mutations with other prognostic biomarkers and their role in cancer progression, OS and potential implementation of pTERT mutation screening from liquid biopsies in clinical settings.

\section{Telomeres and function of telomerase}

The telomerase reverse transcriptase (TERT) gene, located on chromosome $5 \mathrm{p} 15.33$, encodes the catalytic subunit of telomerase, a ribonucleoprotein enzyme essential for the replication of chromosome termini and extension of telomeres in eukaryotic organisms. This function is required for continued cell division and is implicated in cell immortality. Telomeres are chromosome termini that contain repetitive DNA sequences (TTAGGG). The repetitive telomere DNA hexamers occur at chromosomal 3'-ends and can be hundreds and thousands of copies in repetition (Moyzis et al. 1988). Telomeres, without the presence of telomerase function, become progressively shorter during each successive cell division. Loss of telomere length beyond a certain point may cause chromosomal instability and genomic rearrangement. Thus, telomere shortening has important implications for cell proliferation. Once telomere length has reached a critical size (the Hayflick limit) through serial cell divisions, normal cells will undergo irreversible cell cycle arrest, referred to as senescence (Becker and Haferkamp 2013; Hayflick 1965). Senescence prevents further cell proliferation and DNA replication, protecting cells from genetic mutations and chromosome rearrangements which could result in oncogenesis. Telomerase counters telomere loss by stabilising and elongating telomeres through the addition of the telomere repeat of TTAGGG to the $3^{\prime}$ ends of human chromosomes (Blackburn 2005).

Telomerase is turned off in most normal adult human cells due to the transcriptional repression of the TERT promoter and are only consistently active in proliferative cells such as germline tissue (ovary and testis), lymphoid lineage-committed progenitor cells, at a low level in normal peripheral leukocytes (including lymphocytes) and bone marrow (Broccoli et al. 1995; Kim et al. 1994; Weng et al. 1996). Reactivation of telomere maintenance mechanisms via telomerase expression is essential for the transformation of normal cells into cancer cells allowing for unlimited cell division and immortality (Counter et al. 1992). In approximately $90 \%$ of cancers immortality is achieved by reactivation of telomerase, involving reactivation of the TERT gene expression. The remaining cancers use an alternate telomere lengthening (ALT) pathway where homologous recombination occurs to maintain the telomere length (Cesare and Reddel 2010; Heaphy et al. 2011; Patel et al. 2016; Shay and Bacchetti 1997). Reactivation of telomerase reverse transcriptase via $P T E R T$ alterations plays a pivotal role in gliomas with $p T E R T$ mutations found in $80-90 \%$, correlating with higher TERT mRNA and protein expression, and subsequent increased telomerase activity. (Borah et al. 2015; Huang et al. 2015; Killela et al. 2013).

\section{Telomerase promoter mutations}

The TERT gene is located on the short arm of chromosome 5 and consists of 16 exons and 15 introns (Cong et al. 1999). The $p T E R T$, embedded in a CpG island, located from -1800 to +2300 relative to the ATG start codon, is rich in binding motifs for various transcription factors (Cong et al. 1999) (Fig. 1). In normal human cells pTERT is unmethylated at the DNA level, while almost all cancer cells harbour methylated promoter regions. While promoter methylation commonly represses transcription, it results in upregulation of TERT expression, possibly by preventing binding of transcriptional repressors to $p T E R T$ (Lee et al. 2020).

Several studies have identified two specific promoter point mutations (cytosine to thymine substitution), chr5:1,295,228 $\mathrm{C}>\mathrm{T}$ and chr5:1,295,250 C > T (also denoted C228T and $\mathrm{C} 250 \mathrm{~T})$ in cancer cells implicated in the activation of telomerase (Horn et al. 2013; Huang et al. 2013). These two mutations are mutually exclusive. Either mutation increases $T E R T$ expression, and consequently telomerase activity, and are thought to contribute to tumourigenesis by overcoming cellular senescence and inducing cell immortalisation (Brennan et al. 2013; Huang et al. 2013, 2015). At the molecular level, both $P T E R T$ mutations create an identical 11 base pair sequence (CCCGGAAGGGG). This constitutes a de novo binding site (Fig. 1) for members of the E26 transformation specific (ETS) family of transcription factors such as the GA-binding protein transcription factor (GABPA), likely involved in transcriptional activation of TERT (Bell et al. 2015; Xiao et al. 2002, 2003). GABPA is central to TERT expression in glioblastoma as it had been shown that the knockdown of GABPA significantly reduced mutant promoter activity without affecting wild-type promoter activity (Bell et al. 2015). Furthermore, a tetramer-forming $\beta 1 \mathrm{~L}$ isoform of GABPA is required for full activation of the mutant pTERT, while GABPA $\beta 1 \mathrm{~L}$ does not act on the wild-type pTERT to induce TERT expression in cell culture experiments (Mancini et al. 2018). Additionally, a recent study found that in the $B R A F^{V 600 E}$ mutated glioma cells also carrying $p T E R T$ mutation, several members of ETS family were 


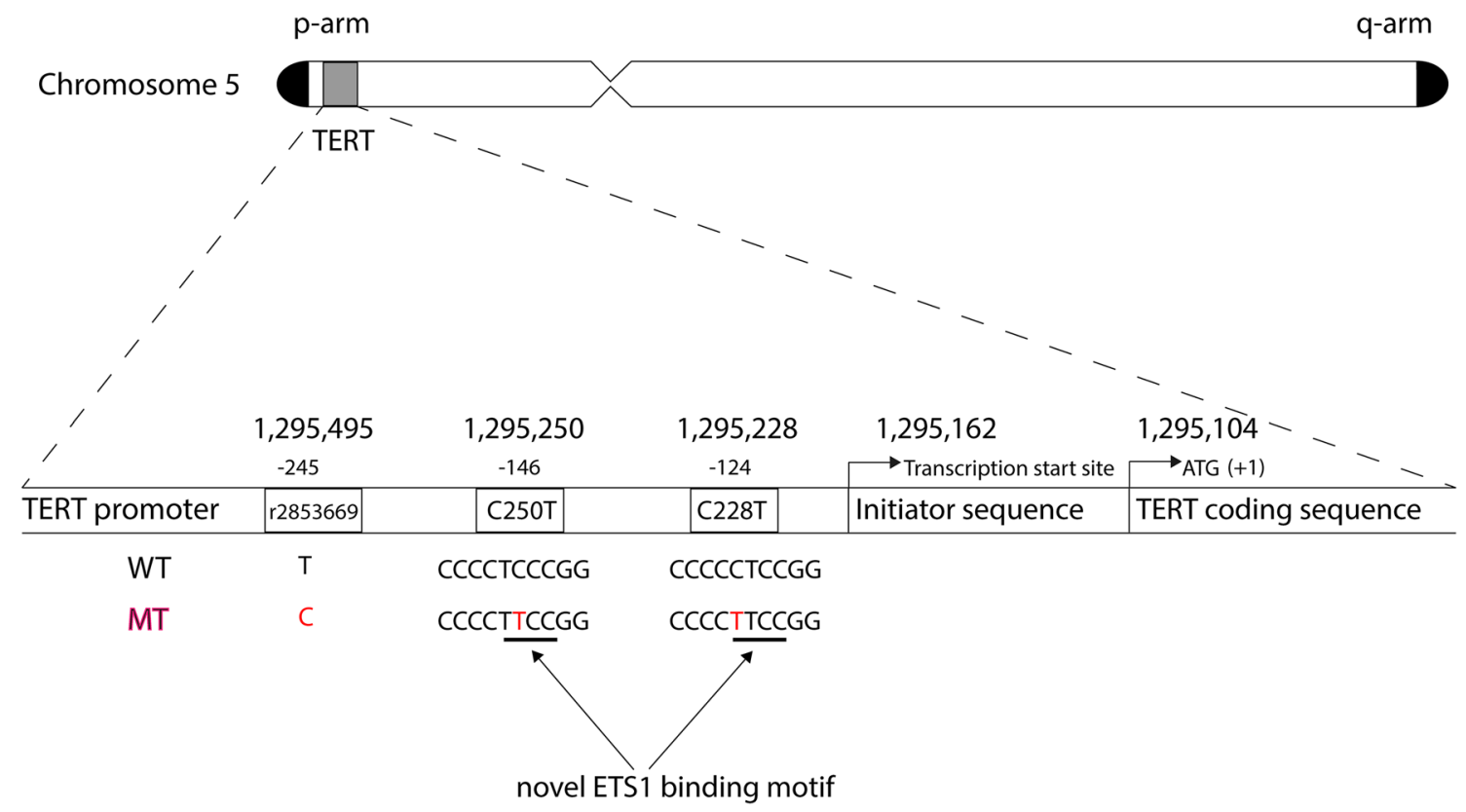

Fig. 1 TERT chromosomal location and regulative motives. Schematic illustration showing the TERT promoter with the novel ETS1 binding sites and cancer-specific TERT promoter mutations C250T and C228T. -146 and -124 indicate the position of the C250T and

hyperactivated: ETS1, GABPA, GABPB, ETV1, ETV4 and ETV5 (Gabler et al. 2019).

\section{pTERT rs2853669 single nucleotide polymorphism (SNP)}

The rs 2853669 SNP of $p T E R T$ is located within a pre-existing ETS2 binding site $5^{\prime}$ to the start codon and close to the $\mathrm{C} 228 \mathrm{~T}$ and $\mathrm{C} 250 \mathrm{~T}$ loci -245 bases $5^{\prime}$ to the transcriptional start ATG codon causing a T $>$ C substitution (Fig. 1).

The rs2853669 variant SNP disrupts the endogenous ETS2 transcriptional site, repressing transcriptional activation of TERT (Hsu et al. 2006; Nencha et al. 2016). The telomerase activity was observed to be lower in the double $\mathrm{C} / \mathrm{C}$ homozygous variant of rs2853669 than that of wild type T/T homozygotes indicating disruption of ETS2 binding site and reduced expression of TERT (Hsu et al. 2006).

rs 2853669 is associated with poorer prognosis and OS, despite lack of association with risk of developing GBM (Mosrati et al. 2015; Spiegl-Kreinecker et al. 2015). This may be due to the rs2853669 SNP modulating negative effects of other oncogenic driver mutation pathways (Mosrati et al. 2015; Spiegl-Kreinecker et al. 2015). A study of 126 GBM patients, showed that the subgroup of patients with wild-type TERT promoter who were also carriers for rs 2853669 had longer median survival than those who were non-carriers for rs2853669 (43.5 vs 20.4 months)
C228T mutations upstream, respectively, in relation to the start of the TERT coding sequence ATG, indicated as +1 . WT wild-type $M T$ mutation

(Spiegl-Kreinecker et al. 2015). However, when the homozygous CC rs2853669 SNP variant was found survival was significantly shorter, particularly if coinciding with either the $\mathrm{C} 228 \mathrm{~T}$ or the C250T pTERT mutation, which correlated with a very short overall survival median of 8.1 months (Spiegl-Kreinecker et al. 2015). These findings were corroborated by another study showing that patients with homozygous CC rs2853669 SNP variant in the presence of pTERT mutation had a similar short overall survival median of 8.2 months (Mosrati et al. 2015). Together these studies imply that the homozygous CC rs 2853669 genotype acts as an independent predictor of short patient survival in $P T E R T$ mutated patients.

Interestingly, data from other studies are conflicting, regarding the survival impact of homozygous, wild type TT rs2853669 SNP with or without pTERT mutation (Batista et al. 2016; Simon et al. 2014) (Nencha et al. 2016) indicating further research is required to clarify the impact of this SNP on GBM patient survival.

\section{PTERT mutations in cancer}

While $p T E R T$ mutations are absent in normal human cells (Kim et al. 1994), they are common in many cancers including in glioblastoma (Kim et al. 1994; Liu et al. 2013) (Table 1). pTERT mutations were significantly associated with the higher mean age at diagnosis in brain cancers (Vinagre et al. 2013). 
Table 1 Prevalence of $p T E R T$ mutations and their role in oncogenesis and patient outcomes

\begin{tabular}{|c|c|c|c|c|c|}
\hline Cancer & Sample & $\begin{array}{l}\text { Number of } \\
\text { patients with } \\
\text { C228T (\%) }\end{array}$ & $\begin{array}{l}\text { Number of } \\
\text { patients with } \\
\text { C250T }(\%)\end{array}$ & $\begin{array}{l}\text { Number of patients with } \\
\text { C228T and/or C250T } \\
(\%)\end{array}$ & Outcome/conclusion \\
\hline Brain - Glioma & Tissue & N/A & N/A & $93 / 199(46.7 \%)$ & $\begin{array}{l}\text { Radiomics may be used to predict } \\
\text { some molecular subtypes, includ- } \\
\text { ing the } p T E R T \text { mutation positive } \\
\text { and IDH1/2 mutation subtype, } \\
\text { with currently limited accuracy. } \\
\text { (Arita et al. 2018) }\end{array}$ \\
\hline Brain - Glioma & Tissue & $32 / 67(47.8 \%)$ & $6 / 67(9.0 \%)$ & $\begin{array}{l}\text { All 38/67 (56.7\%) } \\
\text { Grade II 3/9 (33.3\%) } \\
\text { Grade III 8/16 (50\%) } \\
\text { Grade IV } 27 / 42(64.3 \%)\end{array}$ & $\begin{array}{l}\text { Patients with } p T E R T \text { mutation } \\
\text { demonstrated significantly } \\
\text { reduced OS and PFS (median } \\
15 \text { months and } 5 \text { months) as com- } \\
\text { pared with those in } p T E R T \text { wild } \\
\text { type patients (median } 33 \text { months } \\
\text { and } 31 \text { months) (log rank test: } \\
\mathrm{P}=0.031 \text {, and } \mathrm{P}=0.008 \text {, respec- } \\
\text { tively) } \\
\text { In grade II tumours, MGMT- } \\
\text { unmethylated/pTERT-mutated } \\
\text { was strongly associated with } \\
\text { worse prognosis. (Kim et al. } \\
\text { 2018) }\end{array}$ \\
\hline Brain - Glioma & Tissue & $24 / 56(42.9 \%)$ & $10 / 56(17.9 \%)$ & $34 / 56(60.7 \%)$ & $\begin{array}{l}\text { pTERT mutations are more com- } \\
\text { mon in tumours with high SEL1L } \\
\text { expression, which is associated } \\
\text { with unfavourable prognosis } \\
\text { and worse response to combined } \\
\text { radiotherapy and adjuvant temo- } \\
\text { zolomide chemotherapy (Mellai } \\
\text { et al. 2020) }\end{array}$ \\
\hline Brain - Glioma & Tissue & $59 / 92(64.1 \%)$ & $20 / 92(21.7 \%)$ & $72 / 92(85.9 \%)$ & $\begin{array}{l}\text { C228T and C250T were sig- } \\
\text { nificantly associated with shorter } \\
\text { survival in univariate analysis } \\
\text { (median } 11 \text { vs. } 20 \text { months } \\
p=0.002 \text { and } 12 \text { vs. } 20 \text { months, } \\
p=0.04 \text { for C228T and C250T, } \\
\text { respectively) compared to wild } \\
\text { type tumours (Mosrati et al. } \\
\text { 2015) }\end{array}$ \\
\hline Brain - Glioma All & Tissue & $274 / 887(30.9 \%)$ & $84 / 887(9.5 \%)$ & & \multirow{8}{*}{$\begin{array}{l}\text { pTERT mutations were detected at } \\
\text { a low frequency in Astrocytomas } \\
\text { and high in Oligodendroglio- } \\
\text { mas. } p T E R T \text { mutations were } \\
\text { inversely correlated with IDH1/2 } \\
\text { mutation. Patients with C250T } \\
\text { pTERT mutations tended to have } \\
\text { longer survival that those with } \\
\text { the C225T mutation. The rate } \\
\text { of C250T mutations in newly } \\
\text { diagnosed gliomas was twice } \\
\text { that of recurrent gliomas (You } \\
\text { et al. 2017) }\end{array}$} \\
\hline Anaplastic astrocytomas & & N/A & N/A & $12 / 37(32.4 \%)$ & \\
\hline Anaplastic oligoastrocytomas & & $N / A$ & N/A & $34 / 83(41 \%)$ & \\
\hline Anaplastic oligodendrogliomas & & $N / A$ & N/A & $10 / 19(52.63 \%)$ & \\
\hline Oligoastrocytomas & & $N / A$ & N/A & $112 / 225(54.2 \%)$ & \\
\hline Oligodendrogliomas & & $N / A$ & N/A & $53 / 70(75.7 \%)$ & \\
\hline Primary GBMs & & $N / A$ & N/A & $89 / 199(44.7 \%)$ & \\
\hline Secondary GBMs & & $N / A$ & N/A & $15 / 51(29.4 \%)$ & \\
\hline Brain-Glioblastoma & Tissue & $48 / 74(64.86)$ & $14 / 74(18.92)$ & $62 / 74(83.78)$ & $\begin{array}{l}\text { Plays a role in tumourigenesis and } \\
\text { pathogenesis of glioblastoma } \\
\text { (Liu et al. 2013) }\end{array}$ \\
\hline Brain-Glioblastoma & Tissue & $17 / 43(39.5 \%)$ & $5 / 43(11.6 \%)$ & $22 / 43(51.2 \%)$ & $\begin{array}{l}\text { TERT mRNA expression higher } \\
\text { in patients with } p T E R T \text { muta- } \\
\text { tions } \mathrm{C} 228 \mathrm{~T}(\mathrm{P}<0.0001) \mathrm{C} 250 \mathrm{~T} \\
(\mathrm{P}=0.0004) \text { (Huang et al. } 2015)\end{array}$ \\
\hline
\end{tabular}


Table 1 (continued)

\begin{tabular}{|c|c|c|c|c|c|}
\hline Cancer & Sample & $\begin{array}{l}\text { Number of } \\
\text { patients with } \\
\text { C228T (\%) }\end{array}$ & $\begin{array}{l}\text { Number of } \\
\text { patients with } \\
\text { C250T }(\%)\end{array}$ & $\begin{array}{l}\text { Number of patients with } \\
\text { C228T and/or C250T } \\
(\%)\end{array}$ & Outcome/conclusion \\
\hline Brain All & Tissue & N/A & N/A & $68 / 124(54.8 \%)$ & \multirow{6}{*}{$\begin{array}{l}\text { pTERT mutations correlated with } \\
\text { telomerase activation and com- } \\
\text { mon in glioblastoma, oligoden- } \\
\text { droglioma, and medulloblastoma } \\
\text { (Huang et al. 2015) }\end{array}$} \\
\hline Glioblastoma & & N/A & N/A & $47 / 56(83.9 \%)$ & \\
\hline Oligodendroglioma & & N/A & N/A & $7 / 10(70 \%)$ & \\
\hline Diffuse Astrocytoma & & N/A & N/A & $8 / 40(20 \%)$ & \\
\hline Anaplastic Astrocytoma & & N/A & N/A & $4 / 12(33.3 \%)$ & \\
\hline Medulloblastoma & & N/A & N/A & $2 / 6(33.3 \%)$ & \\
\hline Brain All & & $101 / 166(60.8 \%)$ & $20 / 166(12.0 \%)$ & $124 / 168(73.8 \%)$ & \multirow{4}{*}{$\begin{array}{l}p T E R T \text { mutations were associated } \\
\text { with poorer OS in glioblas- } \\
\text { toma }(P=0.003) \text { and anaplastic } \\
\text { astrocytoma }(P=0.001) \text {, but not } \\
\text { in oligodendroglioma (Lee et al. } \\
2017)\end{array}$} \\
\hline Glioblastoma & & $43 / 65(66.2 \%)$ & $11 / 65(16.9 \%)$ & $57 / 65(87.7 \%)$ & \\
\hline Oligodendroglioma & & $55 / 63(87.3 \%)$ & $8 / 63(12.7 \%)$ & $63 / 65(96.9 \%)$ & \\
\hline Anaplastic Astrocytoma & & $3 / 38(7.9 \%)$ & $1 / 38(2.6 \%)$ & $4 / 38(10.5 \%)$ & \\
\hline
\end{tabular}

N/Anot available, $c f D N A$ cell-free DNA, $P F S$ progression-free survival

The C228T mutation is the more prevalent cancer-associated pTERT-variant (see Table 1) (Huang et al. 2013; Johanns et al. 2016; Palsgrove et al. 2019). When 887 gliomas were analysed for pTERT mutations, C250T was found in $9.5 \%$ and C228T in $30.9 \%$ of all gliomas, with oligodendrogliomas having the highest proportion of mutations (both mutations combined) of 75.7\% (You et al. 2017). pTERT C228T was associated with poorer OS compared to patients with $\mathrm{C} 250 \mathrm{~T}$ gliomas. Furthermore, the study indicated that the $p T E R T$ mutation frequency increased with age, and younger patients with $p T E R T$ mutation had longer OS than older patients with pTERT mutation (Akyerli et al. 2018). Another study examined $128 \mathrm{GBM}$ samples and detected that $86 \%$ had pTERT mutations, $75 \%$ the C228T and $25 \%$ the C250T variant. In this cohort, GBM patients with $p T E R T$ mutations had shorter OS compared to wild-type pTERT patients with median OS 11 versus 20 months, respectively (Mosrati et al. 2015). Other studies confirm this key prognostic role of pTERT mutational status in GBM. (Table 1). Interestingly, an in vitro study has shown that programmable base editing of mutated pTERT blocked the binding of members of the ETS1 transcription factors to the TERT promoter, reduced TERT transcription and TERT protein expression, and induced senescence in glioma cell lines, suggesting that targeting $p T E R T$ mutations could be used as a therapeutic approach in cancer management ( $\mathrm{Li}$ et al. 2020).

\section{pTERT mutations and association with other prognostic biomarkers}

Table 2 summarizes the correlation of pTERT mutations and other key biomarkers in gliomas. One key study examined 299 patients with diffuse gliomas and defined them into four distinct molecular groups: IDH mutation only (33.8\%), pTERT mutation only (31.4\%), IDH-pTERT double mutant (21.4\%) or both wild type (13.4\%) (Akyerli et al. 2018). Isocitrate Dehydrogenase $(I D H)$ mutations are a welldescribed favourable prognostic marker in glioma (Vuong et al. 2017). Patients with the IDH-pTERT double mutations had better overall survival than those with $I D H$ only mutations (Akyerli et al. 2018). Moreover, 96.3\% of patients with the IDH-pTERT double mutations were also positive for $1 \mathrm{p} / 19 \mathrm{q}$ co-deletions. All patients that had $1 \mathrm{p} / 19 \mathrm{q}$ codeletions also harboured $p T E R T$ mutations. More importantly, the analysis showed that the $p T E R T$ only mutations group was associated with older age and poor OS (Akyerli et al. 2018). These results are supported by the findings of Heidenreich et al., who showed in their cohort of 303 gliomas that the patients with only $p T E R T$ mutations had worse OS, while the patients with both IDH and pTERT mutations had the best OS (Heidenreich et al. 2015). Interestingly, one study showed that combined analysis of IDH1/2 and $p T E R T$ mutational status could be used to distinguish if a glial lesion is glioma or reactive glioma. The study reported that reactive gliosis samples did not contain C228T or C250T mutations in the TERT promoter region, while $78 \%$ of IDH wild type gliomas were found to have $p T E R T$ mutation (Hewer et al. 2020).

A study by You and colleagues analysed the rates and clinical outcomes of combined alterations of pTERT mutations and other key markers including IDH1/2, EGFR, TP53, PTEN, MGMT and 1p19q, in gliomas. The prognostic impact of $p T E R T$ mutations varied between groups, with improved prognosis in patients with both pTERT and IDH mutations, but the poorest survival in patients with $p T E R T$ mutation and EGFR amplification (You et al. 2017). 


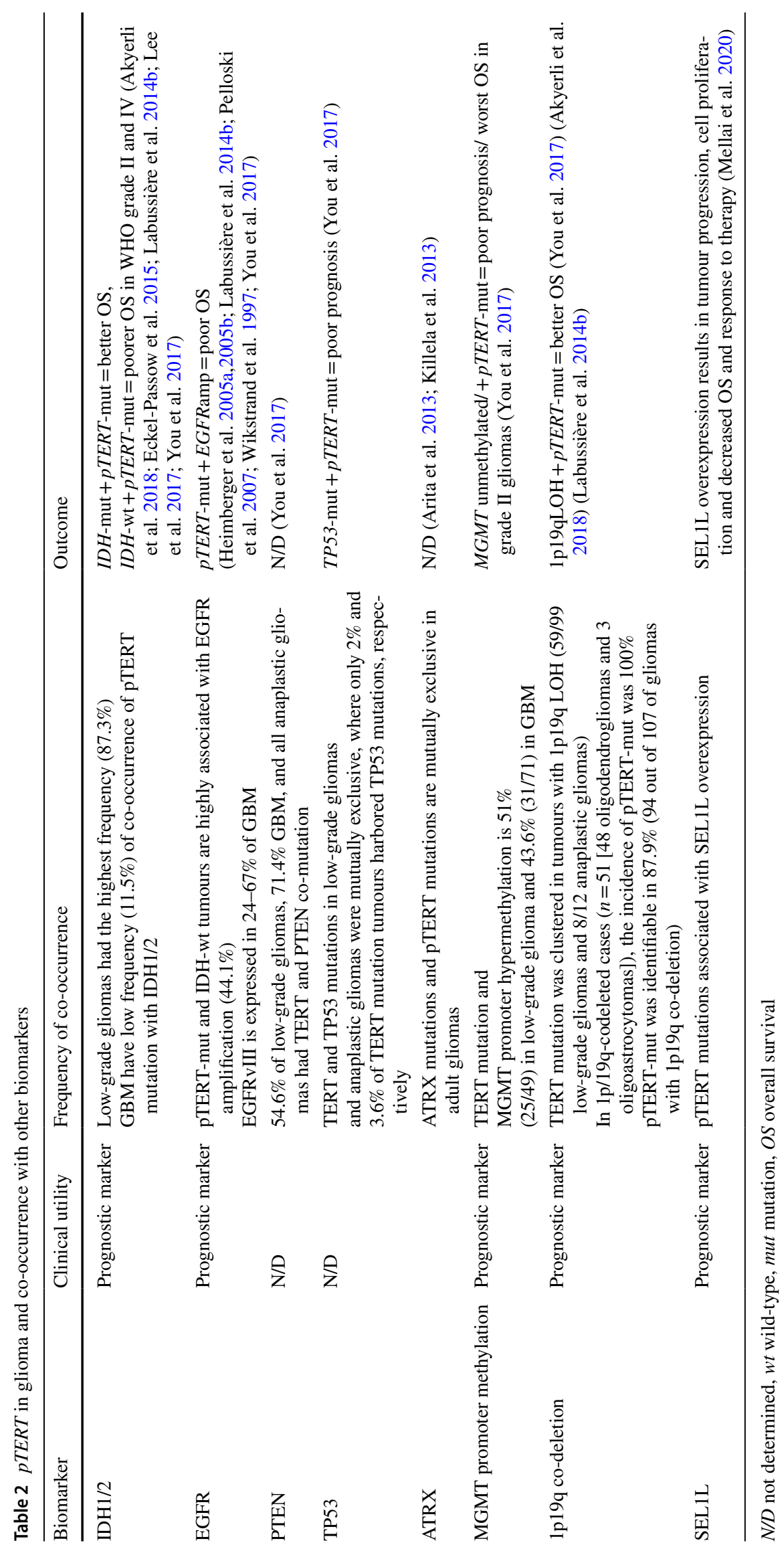


In contrast, in ALT positive astrocytomas pTERT and IDH1 mutations appeared mutually exclusive and $p T E R T$ mutations were generally associated with $I D H 1$ wild-type astrocytoma (Ferreira et al. 2020). This study indicates that ALT may be the major telomere maintenance mechanism in $I D H 1$ mutation astrocytoma resulting in histidine substitution at arginine $132\left(\mathrm{IDH} 1^{\mathrm{R} 132 \mathrm{H}}\right)$ mutated astrocytomas and that IDH $1^{\mathrm{R} 132 \mathrm{H}}$ downregulates ATRX expression in vitro resulting in ALT (Ferreira et al. 2020). This potentially contributes to the association of IDH $1^{\mathrm{R} 132 \mathrm{H}}$ mutations, $\alpha$-thalassemia/mental retardation syndrome $\mathrm{X}$-linked (ATRX) loss and ALT (Ferreira et al. 2020). The ATRX gene is frequently mutated in gliomas and while its role in gliomagenesis is not clear so far, it is thought to be associated with ALT (Koschmann et al. 2016; Rizzo et al. 2009). A report into the prevalence of ALT mechanism in human cancers found $11 \%$ of adult glioblastoma rely on ALT, while the majority of adult glioblastoma relies on the reactivation of telomerase (Heaphy et al. 2011).

As mentioned above, there is a correlation between $p T E R T$ and SNP variant rs2853669, with SNP alone associated with improved OS in glioma, while $p T E R T$ decreases OS and $p T E R T$ together with wild-type SNP rs2853669 further lowers OS in glioma (Rachakonda et al. 2013).

Suppressor of Lin-12-like protein (C. elegans) (SEL1L) is recently emerging as a potential biomarker in brain cancer. SEL1L expression is associated with glioma proliferation and severity, as seen in the human brain glioblastoma cells cultured in vitro and in a formalin-fixed paraffin sections of glial tumours (Cattaneo et al. 2014). A recent study has shown that $P T E R T$ mutations are associated with SEL1L overexpression in glioblastoma; high SEL1L immunoreactivity correlates with tumour progression, cell proliferation, decreased OS and poorer response to therapy (Mellai et al. 2020). Further, it was proposed that SEL1L could be an important biomarker in $p T E R T$ mutant/EGFR amplified/IDH wild-type subgroup of glioblastoma (Mellai et al. 2020).

\section{Detection of TERT promoter mutations in liquid biopsies}

Currently brain cancer is diagnosed via magnetic resonance imaging (MRI) and, or computerised tomography (CT). A definite diagnosis of glioblastoma is obtained by histopathological confirmation at surgery or biopsy. There is an expanding role for molecular biomarker tests to aid treatment decisions and prognostication such as $I D H 1 / 2$ mutation, MGMT promoter methylation, $1 \mathrm{p} 19 \mathrm{q}$ co-deletion, pTERT (C228T, C250T), H3.3 (K27M and G34R/V), as well as Next Generation Sequencing Glioma Panel using these tumour tissue samples. Improved biomarker testing is of increasing interest in clinical trials worldwide in glioblastoma (such as Visual Study of Molecular Genotype in Glioma Evolution, NCT03750890) and other cancers (Visual Study of Molecular Genotype in Glioma Evolution).

However, tissue biopsies may poorly reflect tumour heterogeneity. Further, these biopsies are invasive and cancer patient condition or tumour location may be risky and/or prohibitive.

Liquid biopsy is an alternative way of examining molecular tumour profiles and utilises blood, cerebrospinal fluid (CSF), urine and other bodily fluids for detection and isolation of circulating tumour cells (CTCs) and circulating tumour DNA (ctDNA) from cancer patients. ctDNA release into blood and bodily fluids depend on the location of the tumour, size and the vascular infiltration of the tumour (Haber and Velculescu 2014). Analysis of ctDNA in real time can provide important molecular insights into the tumour composition, heterogeneity, prognostic biomarkers and their association with other clinically relevant cancer biomarkers. Previous studies have shown that the levels of ctDNA present in liquid biopsies vary from patient to patient, however, the relative levels on repeated sampling in a single patient can indicate cancer progression (Diehl et al. 2008). Monitoring tumour dynamics via ctDNA before, during and post-treatment serves as an important tool. Using sensitive techniques such as droplet digital PCR has made this much easier as it can detect minute amounts of ctDNA in liquid biopsies (Ding et al. 2018). Accordingly, the potential of screening for $p T E R T$ mutations as biomarkers for future individualised therapies for patients should be considered. Increasing technological development, in the area of liquid biopsies, allow for a more convenient method of biomarker detection and are increasingly being adopted in clinical trials worldwide.

In brain cancer, liquid biopsy analysis may be more challenging due to the blood-brain barrier preventing release of tumour derived entities into the blood. Nevertheless, we and others have shown that CTCs and ctDNA can be isolated and analysed from brain cancer patients (Lynch 2020; Macarthur et al. 2014; Müller et al. 2014; Sareen et al. 2020; Sullivan et al. 2014). Further, ctDNA detection could predict the recurrence of disease earlier than conventional methods of monitoring in many cancer types (Ding et al. 2019; Gao et al. 2016; McEvoy et al. 2019; Sozzi et al. 2001; Tie et al. 2016; Wang et al. 2015). A study analysing the overall detection rate of ctDNA in the 419 primary brain tumours, including 222 glioblastomas, have shown that the detection of genomic alteration via ctDNA is achievable, with 211 patients showing some genomic alteration (Piccioni et al. 2019). Another study, looking at the clinical utility of plasma cell-free DNA (cfDNA) in adult patients with newly diagnosed glioblastoma, have determined that the patients had higher plasma cfDNA concentration at baseline (Bagley et al. 2020). The high baseline plasma cfDNA is associated 
with the worse progression-free survival with a median of 4.9 months vs 9.5 months, inducating that the plasma taken at that point may be an informative prognostic tool (Bagley et al. 2020). Furthermore, a recent study on diffuse gliomas, indicate that the presence of the ctDNA in CSF may serve as an early indicator of progression in glioma (Miller et al. 2019).

Thus, liquid biopsy may play a major role in diagnosis, monitoring, assessing disease progression and predicting response to brain cancer treatments in the future. Recently, ctDNA isolated from plasma has been successfully screened for $p T E R T$ mutations in various cancers, including metastatic melanoma, hepatocellular carcinoma, myxoid liposarcomas and urothelial cancer (Barata et al. 2017; Braig et al. 2019; Calapre et al. 2019; Ikeda et al. 2018; McEvoy et al. 2017). $p T E R T$ mutations can be detected using digital droplet PCR assays implying its potential utility in brain cancer therapy decision making and in progression monitoring (Braig et al. 2019; Calapre et al. 2019; Deniel et al. 2019; Hayashi et al. 2019; Wan et al. 2017).

\section{Conclusion}

pTERT mutations, C228T and C250T, frequently occur in many cancers, including brain cancers such as glioblastoma (Arita et al. 2013; Kim et al. 1994; Panebianco et al. 2019; Vinagre et al. 2013). These mutations induce the novel ETS1 binding site, which increases the expression of telomerase directly contributing to tumorigenesis, and are associated with poorer OS (Bell et al. 2015; Huang et al. 2013). Presence of $p T E R T$ mutations correlates with the presence of other biomarkers, such as IDH1, 1p19q, TP53, EGFR. Screening for the presence of variants in all of these genes may help prognosticate patients which may, in turn, improve clinical decision making (Arita et al. 2018, 2016; Heidenreich et al. 2015; Hewer et al. 2020; Kim et al. 2018; Mosrati et al. 2015; Pelloski et al. 2007; Spiegl-Kreinecker et al. 2015; Yuan et al. 2016). Whilst utility of liquid biopsies, as a minimally invasive approach, in the brain cancer setting is in its infancy, CTC and ctDNA analyses in brain cancer are increasingly common (Sareen et al. 2020). This review shows the detection of ctDNA and cfDNA in plasma and CSF of glioma patients is possible, and hand in hand with improved molecular detection techniques may become an important tool in determining prognosis and progressionfree survival (Bagley et al. 2020; Miller et al. 2019).

The investigation of the profile of various biomarkers may hold clues to better understand tumour biology and may predict benefit of potential combination therapies. This area should therefore be a focus of further studies.
Funding This work was supported by a grant (13/TRC/1-01) from the Cancer Institute NSW through the CONCERT Translational Cancer Research Centre, SAJ is a recipient of an Ingham Institute $\mathrm{PhD}$ Scholarship, generated by the Liverpool Catholic Club. BP is funded through a Clinical Academic Group Seed Grant from the Sydney Partnership for Health, Education, Research and Enterprise (SPHERE).

\section{Compliance with ethical standards}

Conflict of interest The authors declare that there is no conflict of interest regarding the publication of this paper.

Open Access This article is licensed under a Creative Commons Attribution 4.0 International License, which permits use, sharing, adaptation, distribution and reproduction in any medium or format, as long as you give appropriate credit to the original author(s) and the source, provide a link to the Creative Commons licence, and indicate if changes were made. The images or other third party material in this article are included in the article's Creative Commons licence, unless indicated otherwise in a credit line to the material. If material is not included in the article's Creative Commons licence and your intended use is not permitted by statutory regulation or exceeds the permitted use, you will need to obtain permission directly from the copyright holder. To view a copy of this licence, visit http://creativecommons.org/licenses/by/4.0/.

\section{References}

Akyerli CB et al (2018) Use of telomerase promoter mutations to mark specific molecular subsets with reciprocal clinical behavior in IDH mutant and IDH wild-type diffuse gliomas. J Neurosurg 128:1102-1114. https://doi.org/10.3171/2016.11.Jns16973

Arita $\mathrm{H}$ et al (2013) Upregulating mutations in the TERT promoter commonly occur in adult malignant gliomas and are strongly associated with total 1p19q loss. Acta Neuropathol 126:267-276. https ://doi.org/10.1007/s00401-013-1141-6

Arita $\mathrm{H}$ et al (2016) A combination of TERT promoter mutation and MGMT methylation status predicts clinically relevant subgroups of newly diagnosed glioblastomas . Acta Neuropathologica Commun 4:79. https://doi.org/10.1186/s40478-016-0351-2

Arita $\mathrm{H}$ et al (2018) Lesion location implemented magnetic resonance imaging radiomics for predicting IDH and TERT promoter mutations in grade II/III gliomas. Scient Rep 8:1-10

Bagley SJ et al (2020) Clinical utility of plasma cell-Free DNA in adult patients with newly diagnosed glioblastoma: a pilot prospective study. Clin Cancer Res 26:397-407. https://doi.org/10.1158/10780432.CCR-19-2533

Barata PC et al (2017) Next-generation sequencing (NGS) of cell-free circulating tumor DNA and tumor tissue in patients with advanced urothelial cancer: a pilot assessment of concordance. Ann Oncol 28:2458-2463. https://doi.org/10.1093/annonc/mdx405

Batista R et al (2016) The prognostic impact of TERT promoter mutations in glioblastomas is modified by the rs 2853669 single nucleotide polymorphism. Int J Cancer 139:414-423

Becker T, Haferkamp S (2013) Molecular mechanisms of cellular senescence. In: Wang Z, Inuzuka H (eds) Senescence and senescence-related disorders. In Tech. https://doi.org/10.5772/54120

Bell RJA et al (2015) Cancer The transcription factor GABP selectively binds and activates the mutant TERT promoter in cancer. Science (New York, NY) 348:1036-1039. https://doi.org/10.1126/scien ce.aab0015 
Blackburn EH (2005) Telomeres and telomerase: their mechanisms of action and the effects of altering their functions. FEBS Lett 579:859-862

Borah S et al (2015) TERT promoter mutations and telomerase reactivation in urothelial cancer. Science 347:1006-1010. https://doi. org/10.1126/science. 1260200

Braig D et al (2019) Genotyping of circulating cell-free DNA enables noninvasive tumor detection in myxoid liposarcomas. Int J Cancer 145:1148-1161. https://doi.org/10.1002/ijc.32216

Brennan Cameron W et al (2013) The Somatic Genomic Landscape of Glioblastoma. Cell 155:462-477. https://doi.org/10.1016/j. cell.2013.09.034

Broccoli D, Young JW, de Lange T (1995) Telomerase activity in normal and malignant hematopoietic cells. Proc Natl Acad Sci 92:9082-9086

Calapre L et al (2019) Locus-specific concordance of genomic alterations between tissue and plasma circulating tumor DNA in metastatic melanoma. Mol Oncol 13:171-184. https://doi. org/10.1002/1878-0261.12391

Cattaneo M et al (2014) Down-modulation of SEL1L, an unfolded protein response and endoplasmic reticulum-associated degradation protein, sensitizes glioma stem cells to the cytotoxic effect of valproic acid. J Biol Chem 289:2826-2838

Cesare AJ, Reddel RR (2010) Alternative lengthening of telomeres: models, mechanisms and implications. Nat Rev Genet 11:319-330

Cong Y-S, Wen J, Bacchetti S (1999) The human telomerase catalytic subunit hTERT: organization of the gene and characterization of the promoter. Hum Mol Genet 8:137-142

Counter CM et al (1992) Telomere shortening associated with chromosome instability is arrested in immortal cells which express telomerase activity. EMBO J 11:1921-1929

Deniel A et al (2019) TERTp Mutation Detection in Plasma by Droplet-Digital Polymerase Chain Reaction in Spinal Myxopapillary Ependymoma with Lung Metastases. World Neurosurg 130:405-409. https://doi.org/10.1016/j.wneu.2019.07.111

Diehl F et al (2008) Circulating mutant DNA to assess tumor dynamics. Nat Med 14:985-990. https://doi.org/10.1038/nm.1789

Ding PN et al (2018) Droplet digital PCR based detection of EGFR mutations in advanced lung cancer patient liquid biopsies: a comparison of circulating tumour DNA extraction kits. J Mol Biomarkers Diag. https://doi.org/10.4172/2155-9929.1000397

Ding PN et al (2019) The predictive and prognostic significance of liquid biopsy in advanced epidermal growth factor receptor-mutated non-small cell lung cancer: A prospective study. Lung Cancer 134:187-193. https://doi.org/10.1016/j.lungc an.2019.06.021

Eckel-Passow JE et al (2015) Glioma groups based on 1p/19q, IDH, and TERT promoter mutations in tumors. N Engl J Med 372:2499-2508. https://doi.org/10.1056/NEJMoa1407279

Ferreira MSV et al (2020) Alternative lengthening of telomeres is the major telomere maintenance mechanism in astrocytoma with isocitrate dehydrogenase 1 mutation. J Neurooncol 1:1-14

Gabler L et al (2019) TERT expression is susceptible to BRAF and ETS-factor inhibition in BRAFV600E/TERT promoter doublemutated glioma. Acta Neuropathol Commun 7:128. https://doi. org/10.1186/s40478-019-0775-6

Gao F et al (2016) Circulating tumor cell is a common property of brain glioma and promotes the monitoring system. Oncotarget 7:71330-71340. https://doi.org/10.18632/oncotarget.11114

Haber DA, Velculescu VE (2014) Blood-based analyses of cancer: circulating tumor cells and circulating tumor DNA. Cancer Discov 4:650-661. https://doi.org/10.1158/2159-8290.Cd-13-1014

Hanahan D, Weinberg RA (2011) Hallmarks of cancer: the next generation. Cell 144:646-674. https://doi.org/10.1016/j.cell.2011.02.013
Hayashi Y et al (2019) Diagnostic potential of TERT promoter and FGFR3 mutations in urinary cell-free DNA in upper tract urothelial carcinoma. Cancer Sci 110:1771-1779. https://doi. org/10.1111/cas. 14000

Hayflick L (1965) The limited in vitro lifetime of human diploid cell strains. Exp Cell Res 37:614-636. https://doi.org/10.1016/00144827(65)90211-9

Heaphy CM et al (2011) Prevalence of the alternative lengthening of telomeres telomere maintenance mechanism in human cancer subtypes. Am J Pathol 179:1608-1615. https://doi.org/10.1016/j. ajpath.2011.06.018

Heidenreich B et al (2015) TERT promoter mutations and telomere length in adult malignant gliomas and recurrences. Oncotarget 6:10617-10633. https://doi.org/10.18632/oncotarget.3329

Heimberger AB et al (2005a) Prognostic effect of epidermal growth factor receptor and EGFRvIII in glioblastoma multiforme patients. Clin Cancer Res 11:1462-1466

Heimberger AB et al (2005b) The natural history of EGFR and EGFRvIII in glioblastoma patients. J Trans Med 3:38

Hewer E et al (2020) TERT promoter mutation analysis to distinguish glioma from gliosis. J Neuropathol Exp Neurol 79:430-436. https ://doi.org/10.1093/jnen/nlaa004

Horn $\mathrm{S}$ et al (2013) TERT promoter mutations in familial and sporadic melanoma. Science 339:959-961

Hsu CP et al (2006) Ets2 binding site single nucleotide polymorphism at the hTERT gene promoter-effect on telomerase expression and telomere length maintenance in non-small cell lung cancer. Eur J Cancer 42:1466-1474. https://doi.org/10.1016/j.ejca.2006.02.014

Huang FW et al (2013) Highly recurrent TERT promoter mutations in human melanoma. Science 339:957-959

Huang D-S et al (2015) Recurrent TERT promoter mutations identified in a large-scale study of multiple tumour types are associated with increased TERT expression and telomerase activation. Eur J Cancer 51:969-976

Ikeda S, Lim JS, Kurzrock R (2018) Analysis of tissue and circulating tumor DNA by next-generation sequencing of hepatocellular carcinoma: implications for targeted therapeutics. Mol Cancer Ther 17:1114-1122

Johanns TM et al (2016) High incidence of TERT mutation in brain tumor cell lines. Brain Tumor Pathol 33:222-227. https://doi. org/10.1007/s10014-016-0257-5

Killela PJ et al (2013) TERT promoter mutations occur frequently in gliomas and a subset of tumors derived from cells with low rates of self-renewal. Proc Natl Acad Sci 110:6021-6026

Kim NW et al (1994) Specific association of human telomerase activity with immortal cells and cancer. Science 266:2011-2015

Kim HS et al (2018) Clinical implications of TERT promoter mutation on IDH mutation and MGMT promoter methylation in diffuse gliomas. Pathol Res Pract 214:881-888. https://doi.org/10.1016/j. prp.2018.04.002

Koschmann C et al (2016) ATRX loss promotes tumor growth and impairs nonhomologous end joining DNA repair in glioma. Sci Transl Med 8:328ra328-328ra328. https://doi.org/10.1126/scitr anslmed.aac 8228

Labussière $\mathrm{M}$ et al (2014) Combined analysis of $<$ em $>$ TERT $</$ em $>$ $<$ em $>$ EGFR $</$ em $>$ and $<$ em $>$ IDH $</$ em $>$ status defines distinct prognostic glioblastoma classes. Neurology 83:1200. https://doi. org/10.1212/WNL.0000000000000814

Labussière $\mathrm{M}$ et al (2014) TERT promoter mutations in gliomas, genetic associations and clinico-pathological correlations. Br J Cancer 111:2024-2032. https://doi.org/10.1038/bjc.2014.538

Lee $\mathrm{Y}$ et al (2017) The frequency and prognostic effect of TERT promoter mutation in diffuse gliomas. Acta Neuropathol Commun 5:62-62. https://doi.org/10.1186/s40478-017-0465-1 
Lee DD et al (2020) DNA methylation of the TERT promoter and its impact on human cancer. Curr Opin Genet Dev 60:17-24. https ://doi.org/10.1016/j.gde.2020.02.003

Li X et al (2020) Programmable base editing of mutated TERT promoter inhibits brain tumour growth. Nat Cell Biol 22:282-288. https://doi.org/10.1038/s41556-020-0471-6

Liu X et al (2013) Highly prevalent TERT promoter mutations in bladder cancer and glioblastoma. Cell Cycle 12:1637-1638

Lynch D et al (2020) Isolation of circulating tumor cells from glioblastoma patients by direct immunomagnetic targeting. Appl Sci Special Issue. https://doi.org/10.3390/app10093338

Macarthur KM et al (2014) Detection of brain tumor cells in the peripheral blood by a telomerase promoter-based assay. Can Res 74:2152-2159. https://doi.org/10.1158/0008-5472.Can-13-0813

Mancini A et al (2018) Disruption of the beta1L Isoform of GABP reverses glioblastoma replicative immortality in a TERT promoter mutation-dependent manner. Cancer Cell 34:513-528. e518. https://doi.org/10.1016/j.ccell.2018.08.003

McEvoy AC et al (2017) Sensitive droplet digital PCR method for detection of TERT promoter mutations in cell free DNA from patients with metastatic melanoma. Oncotarget 8:78890-78900. https://doi.org/10.18632/oncotarget.20354

McEvoy AC et al (2019) Monitoring melanoma recurrence with circulating tumor DNA: a proof of concept from three case studies. Oncotarget 10:113-122. https://doi.org/10.18632/oncotarget .26451

Mellai M et al (2020) SEL1L plays a major role in human malignant gliomas. J Pathol Clin Res 6:17-29. https://doi.org/10.1002/ cjp 2.134

Miller AM et al (2019) Tracking tumour evolution in glioma through liquid biopsies of cerebrospinal fluid. Nature 565:654-658. https://doi.org/10.1038/s41586-019-0882-3

Mosrati MA et al (2015) TERT promoter mutations and polymorphisms as prognostic factors in primary glioblastoma. Oncotarget 6:16663-16673. https://doi.org/10.18632/oncotarget.4389

Moyzis RK et al (1988) A highly conserved repetitive DNA sequence,(TTAGGG) n, present at the telomeres of human chromosomes. Proc Natl Acad Sci 85:6622-6626

Müller C et al (2014) Hematogenous dissemination of glioblastoma multiforme. Sci Transl Med 6:247ra101. https://doi. org/10.1126/scitranslmed.3009095

Nencha U et al (2016) TERT promoter mutations and rs2853669 polymorphism: prognostic impact and interactions with common alterations in glioblastomas. J Neurooncol 126:441-446. https://doi.org/10.1007/s11060-015-1999-3

Nonoguchi N, Ohta T, Oh J-E, Kim Y-H, Kleihues P, Ohgaki H (2013) TERT promoter mutations in primary and secondary glioblastomas. Acta Neuropathol 126:931-937. https://doi. org/10.1007/s00401-013-1163-0

Palsgrove DN et al (2019) Targeted sequencing of plasmacytoid urothelial carcinoma reveals frequent TERT promoter mutations. Hum Pathol 85:1-9. https://doi.org/10.1016/j.humpa th.2018.10.033

Panebianco F et al (2019) Spectrum of TERT promoter mutations and mechanisms of activation in thyroid cancer. Cancer Med 8:5831-5839

Patel PL et al (2016) Derepression of hTERT gene expression promotes escape from oncogene-induced cellular senescence. Proc Natl Acad Sci USA 113:E5024-E5033. https://doi.org/10.1073/ pnas. 1602379113

Pelloski CE et al (2007) Epidermal growth factor receptor variant III status defines clinically distinct subtypes of glioblastoma. J Clin Oncol 25:2288-2294

Piccioni DE et al (2019) Analysis of cell-free circulating tumor DNA in 419 patients with glioblastoma and other primary brain tumors. CNS Oncol 8:CNS34-CNS34. https://doi.org/10.2217/ cns-2018-0015

Rachakonda PS et al (2013) TERT promoter mutations in bladder cancer affect patient survival and disease recurrence through modification by a common polymorphism. Proc Natl Acad Sci U S A 110:17426-17431. https://doi.org/10.1073/pnas.13105 22110

Rizzo A et al (2009) Stabilization of quadruplex DNA perturbs telomere replication leading to the activation of an ATR-dependent ATM signaling pathway. Nucleic Acids Res 37:5353-5364. https://doi.org/10.1093/nar/gkp582

Sareen $\mathrm{H}$ et al (2020) The role of liquid biopsies in detecting molecular tumor biomarkers in brain cancer patients. Cancers 12:1831

Shay JW, Bacchetti S (1997) A survey of telomerase activity in human cancer. Eur J Cancer 33:787-791. https://doi. org/10.1016/S0959-8049(97)00062-2

Simon M et al (2014) TERT promoter mutations: a novel independent prognostic factor in primary glioblastomas. Neuro-Oncology 17:45-52. https://doi.org/10.1093/neuonc/nou 158

Sozzi G et al (2001) Analysis of circulating tumor DNA in plasma at diagnosis and during follow-up of lung cancer patients. Cancer Res 61:4675-4678

Spiegl-Kreinecker S et al (2015) Prognostic quality of activating TERT promoter mutations in glioblastoma: interaction with the rs2853669 polymorphism and patient age at diagnosis. Neurooncology 17:1231-1240

Stupp R, Tonn J-C, Brada M, Pentheroudakis G, Group EGW (2010) High-grade malignant glioma: ESMO Clinical Practice Guidelines for diagnosis, treatment and follow-up. Ann Oncol 21:v190-v193

Sullivan JP et al (2014) Brain tumor cells in circulation are enriched for mesenchymal gene expression . Cancer Discov 4:1299. https ://doi.org/10.1158/2159-8290.CD-14-0471

Tie J et al (2016) Circulating tumor DNA analysis detects minimal residual disease and predicts recurrence in patients with stage II colon cancer. Sci Trans1 Med 8:346ra392-346ra392

Vinagre J et al (2013) Frequency of TERT promoter mutations in human cancers. Nat Commun 4:1-6

Visual Study of Molecular Genotype in Glioma Evolution. https:// ClinicalTrials.gov/show/NCT03750890

Vuong HG et al (2017) TERT promoter mutation and its interaction with IDH mutations in glioma: Combined TERT promoter and IDH mutations stratifies lower-grade glioma into distinct survival subgroups-A meta-analysis of aggregate data. Crit Rev Oncol Hematol 120:1-9

Wan JCM et al (2017) Liquid biopsies come of age: towards implementation of circulating tumour DNA Nature reviews. Cancer 17:223-238. https://doi.org/10.1038/nrc. 2017.7

Wang J et al (2015) Label-free isolation and mRNA detection of circulating tumor cells from patients with metastatic lung cancer for disease diagnosis and monitoring therapeutic efficacy. Anal Chem 87:11893-11900

Weng NP et al (1996) Regulated expression of telomerase activity in human T lymphocyte development and activation. J Exp Med 183:2471-2479. https://doi.org/10.1084/jem.183.6.2471

Wikstrand CJ et al (1997) Cell surface localization and density of the tumor-associated variant of the epidermal growth factor receptor EGFRvIII. Cancer Res 57:4130-4140

Xiao X et al (2002) Identification and characterization of rapidly dividing U937 clones with differential telomerase activity and gene expression profiles: role of c-Myc/Mad1 and Id/Ets proteins. Leukemia 16:1877

Xiao X et al (2003) Role of Ets/Id proteins for telomerase regulation in human cancer cells. Exp Mol Pathol 75:238-247

You H, Wu Y, Chang K, Shi X, Chen XD, Yan W, Li R (2017) Paradoxical prognostic impact of TERT promoter mutations 
in gliomas depends on different histological and genetic backgrounds. CNS Neurosci Ther 23:790-797. https://doi. org/10.1111/cns.12724

Yuan P et al (2016) Clinical characteristics and prognostic significance of TERT promoter mutations in cancer: a cohort study and a meta-analysis. PLoS ONE. https://doi.org/10.1371/journ al.pone. 0146803
Publisher's Note Springer Nature remains neutral with regard to jurisdictional claims in published maps and institutional affiliations. 